\title{
Bright spots among lakes in the Rideau Valley Watershed, Ontario
}

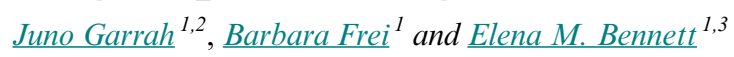

\begin{abstract}
Water quality, of critical importance to the ecological and social health of lake ecosystems, is maintained through complex interactions within lakes as well as between lakes and their watersheds. Often, water quality is managed by working toward improved water clarity, however, our ability to predict water clarity, and to manage lakes for it, is not always as successful as desired. Regional strategies for water clarity improvement often overlook the role of local environmental stewardship actions performed by lake associations on individual lakes across a region. Lake associations can act through directly altering biophysical drivers of clarity or the way that residents act within the system, demonstrating great potential to be incorporated into successful lake scale water quality management plans. We used a "bright spots" lens, in which we focus on those lakes whose water quality is higher than expected, to investigate the relationship between lake associations and water quality on 39 lakes in the Rideau Valley Lake Region (Ontario, Canada). We found that lake associations that are linked to "bright spot" lakes operate in a distinctly different way than other groups in the region, focusing on networking and advocacy activities instead of on ecological management. This points to the importance of working toward networking and advocacy goals as a future for lake stewardship groups in the Rideau Valley and other stewardship groups adapting this approach to their own social-ecological contexts.
\end{abstract}

Key Words: bright spots; Canada; comanagement; environmental stewardship; lake associations; social-ecological systems; water quality

\section{INTRODUCTION}

Water quality is of critical importance in supporting both the ecological integrity and desirable social functions of lake ecosystems. A clear lake, free of algal blooms and excess turbidity, affords a greater diversity of aquatic vegetation (Fee et al. 1996), which in turn creates more opportunities for recreation (Keeler et al. 2012), including sustainable recreational fisheries (Gunn et al. 2001), and higher property values (Gibbs et al. 2002). In contrast, turbid lakes, or those polluted with excess nutrients, can exhibit anoxic conditions, leading to die-offs of significant fish populations (Gunn et al. 2001), and fewer recreational opportunities (Keeler et al. 2012). Water quality also has wide far reaching effects on the human population of the watershed through influences on human health (Keeler et al. 2012), the availability of safe drinking water (Postel and Thompson 2005), hydropower production (Brauman et al. 2007), and regional economic well-being (Gibbs et al. 2002).

Complex interactions within a lake, as well as between a lake and its watershed, drive the water quality of a given lake (Stefan et al. 1989) Many biophysical and ecological factors play a role in determining water quality, including lake depth (Scheffer and van Nes 2007), water color (Gunn et al. 2001, Keeler et al 2012), species composition (Fahnenstiel et al. 1995, Barbiero and Tuchman 2004), and phosphorus loading, itself a result of interactions between biophysical, ecological, and social conditions (Soranno et al. 1996, Tong and Chen 2002). Social factors at play around a lake, including socioeconomic and demographic patterns, development levels, and behaviors of local residents and groups, are also known to influence water quality (Peterson et al. 2003, Kramer 2007, Ostrom 2009).

Lake clarity, the depth of sunlight penetration into the water column, is a commonly used proxy to assess lake water quality (Fee et al. 1996). Clarity has been shown to accurately reflect local scale system dynamics (such as nutrient loading and erosion) as well as larger scale regional or global scale stressors, such as climate change (Gunn et al. 2001). Simple and relatively easy to measure, clarity is a useful monitoring tool although it is strongly related to dissolved organic carbon concentrations at the expense of accurately representing other drivers of water quality (DaviesColley and Smith 2001)

Although many social and ecological drivers of lake water clarity are well-known, our ability to predict and manage lakes for water clarity and quality remains relatively limited (Jeppesen et al. 2005) Some lakes have water quality that differs significantly from predictions based on commonly used social and ecological drivers (Hall and Smol 1996). Additionally, it can be difficult to maintain lakes in a clear water state using established management practices based on these predictors, or, in particular, to restore turbid or polluted lakes to clear water states (Scheffer et al. 1993). This inability to manage apparently well-understood systems might point to missing variables or an incomplete understanding of the systems that drive water clarity (Scheffer and van Nes 2007, Armitage et al. 2009, Post and Geldmann 2018).

One feature that may be being overlooked in management of lake water clarity is the role of local environmental stewardship groups. Stewardship, "the actions taken by individuals, groups, or networks of actors [...] to protect, care for, or responsibly use the environment in pursuit of environmental and/or social outcomes in diverse social-ecological contexts" (Bennett et al. 2018:599), has a unique potential to alter both biophysical drivers of environmental quality and the human behavioral patterns that can affect it (Wolf et al. 2013). Along with social-ecological context, Bennett et al. (2018) identify four key leverage points that shape stewardship outcomes: actors, motivations, capacities, and actions (Bennett et al. 2018). Through these leverage points, groups are able to shape outcomes either through direct interactions with their physical environment or by reshaping the way that people act within the system, from residents' day-to-day

${ }^{1}$ Department of Natural Resource Sciences, McGill University, ${ }^{2}$ Urban Systems Lab, The New School, ${ }^{3}$ McGill School of Environment, McGill University 
actions to management arrangements (Wolf et al. 2013). Despite their large potential capacity to act as agents for lake management, local environmental stewardship groups such as lake associations are a relatively unexplored driver of water quality (Kramer 2007).

The concept of "bright spots," a framework that prompts us to learn from exceptional outliers, can be a useful lens for exploring typically overlooked drivers (Bennett et al. 2016, Post and Geldmann 2018). Through identifying "bright spots," systems or parts of systems that are performing much better than expected relative to the usual predictors, and searching for commonalities among them, scientists can sometimes identify unexplored drivers (Cinner et al. 2016). The bright spots approach has been used to identify previously unexplored social arrangements that were maintaining healthy fisheries on world's coral reefs (Cinner et al. 2016), and to identify socioeconomic attributes of multifunctional agricultural landscapes (Frei et al. 2018).

We used existing data on biophysical and social variables known to be good predictors of water clarity, including dissolved organic carbon (DOC), lake size, percent agricultural land use, and presence of zebra mussels to predict water clarity in 39 lakes in the Rideau Valley, Ontario. We analyzed the residuals of this model to identify bright spots, sites with high magnitude positive residuals and dark spots, sites with high magnitude negative residuals. We then gathered qualitative information on lake association presence, composition, and actions (Kramer 2007, Bennett et al. 2018) to identify whether there were commonalities in stewardship action between bright spot lakes to determine which aspects of stewardship might be playing a role in higher than expected water quality in the bright spot lakes. By highlighting the importance of lake associations in driving positive outcomes for lake clarity and water quality management, the results of this study serve as a template for lake associations and managers setting future priorities for stewardship as a management strategy.

\section{METHODS}

\section{Study area}

The Rideau Valley Watershed is located in Eastern Ontario, spanning roughly from the upland area north of Kingston, and stretching eastwards to Ottawa, draining through the Rideau River into the Ottawa River (Ahmed 2010; Fig. 1). The 39 lakes in our study are those monitored by the Rideau Valley Conservation Authority (RVCA), all situated in the upper reaches of the watershed in Leeds and Grenville, Lanark, and Frontenac Counties. The landscape of the region is a rural-recreational countryside, with agricultural activity (mainly dairy farming) filling in the less dense rural space between lakes with dense, smalllot, single row cottages along the shoreline. As one of the oldest cottage areas in Canada, most of the lakes have highly developed shorelines with multiple public access points; however some monitored lakes remain relatively remote and undeveloped (Halseth and Rosenberg 1995).

\section{Data collection}

We estimated water clarity through existing data available from the RVCA at two different scales: lakes $(n=39)$, and deep point measurement sites within lakes $(n=53$; further referred to as simply sites). Data on water clarity was gathered at sites, with a small number of lakes $(n=6)$ containing more than one site, ranging from two to six. The RVCA measures water clarity via Secchi disk once per month from May to October (Davies-Colley and Smith 2001).

Fig. 1. A map of the study watershed and its location in southern Ontario, with the major cities of Ottawa and Kingston, Ontario and the regional center of Perth, Ontario.

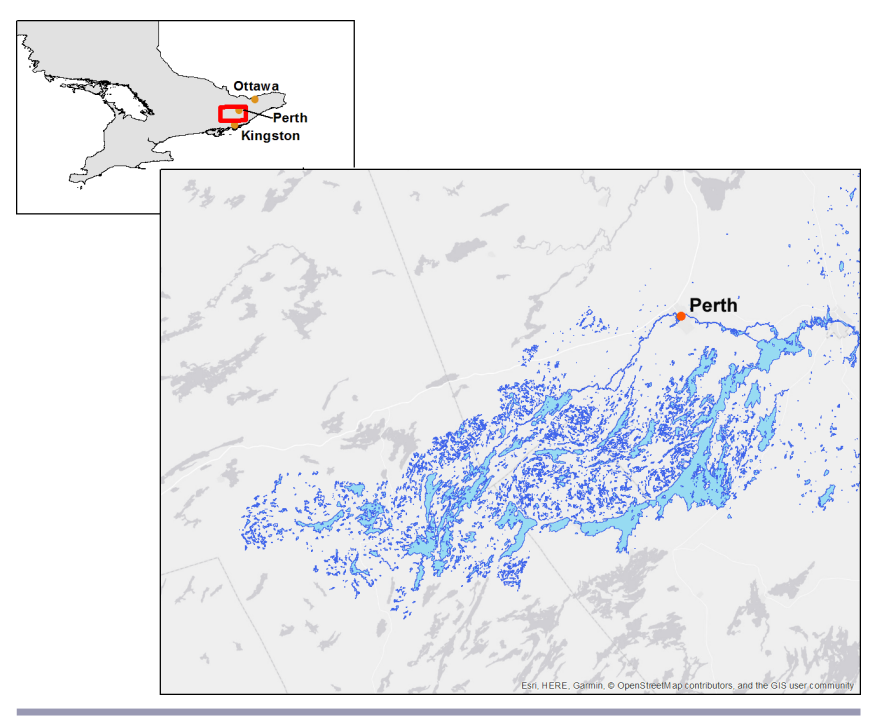

Data for biophysical predictors of water clarity (including DOC, zebra mussel presence, lake surface area, and agricultural land use in the catchment) were taken from an RVCA database of measurements taken between 2001 and 2013 across all 53 sites. DOC, indicating water color (Gunn et al. 2001), was sampled at all sites with a composite bottle sampler, lowered to twice the Secchi disk depth and pulled up, collecting water over the entirety of the eutrophic zone each June. Samples were filtered through a 0.45 micrometer filter into a glass bottle and analyzed at Caducean Environmental Laboratory, Ottawa, Ontario. After data cleaning to account for missing field or laboratory values, 490 observations across all 53 sites were obtained. Status and presence of invasive zebra mussels for all 39 lakes were obtained via direct observation by RVCA. Lake size (Scheffer and van Nes 2007) was calculated using the calculate geometry tool in ArcMap 10. Each catchment was delineated using the Ontario Ministry of Natural Resources and Forestry's online Ontario Flow Assessment Tool (OFAT). In OFAT, each lake's outlet was identified using contour and hydrology network layers and the "create watershed" tool was used to delineate. Percent cover of each land use/land cover category for each catchment was calculated from within OFAT, drawing from the Ontario Land Cover Compilation dataset (Ontario Ministry of Natural Resources and Forestry 2017). The percent agriculture land use in each catchment was drawn from this analysis and used as a proxy for nutrient loading in each lake (Tong and Chen 2002).

\section{Bright spot analysis of water clarity}

We performed all statistical analyses with $\mathrm{R}$ version 3.5.0 (R Core Team 2018). Because Secchi and DOC measurements were normally distributed with even distributions of standardized residuals for each lake and year, we selected a linear mixed effects 
Table 1. The variables of interest about bright spots, indicator used in a survey sent to all 20 lake associations in the Rideau Valley, Ontario, and units of measurement, plus stewardship characteristics drawn from Bennett et al. (2018)'s conceptual framework of local environmental stewardship.

\begin{tabular}{llll}
\hline \hline Variable & Indicator & Units & Stewardship Characteristic \\
\hline Network Connections & $\begin{array}{l}\text { List of groups or organizations } \\
\text { regularly collaborated with } \\
\text { Funding }\end{array}$ & Number & Actors, Capacities: Social Capital \\
& $\begin{array}{l}\text { income } \\
\text { Selecting activities from a list and } \\
\text { designating one as primary }\end{array}$ & Yes/no, categorical & Capacities: Financial Capital \\
Group activities & $\begin{array}{l}\text { Selecting strategies used from list } \\
\text { Likert scale ranking of various } \\
\text { hypothesized motivators } \\
\text { Motivators }\end{array}$ & $\begin{array}{l}\text { Categorical } \\
\text { Likert scale ranking various social scale value } \\
\text { and ecological outcomes }\end{array}$ & Likert scale value \\
Pumber of cottages, number of & Count & Actions \\
residents & $\begin{array}{l}\text { Percentage of year-round residents } \\
\text { Development level }\end{array}$ & $\begin{array}{l}\text { Proportion, categorical selection of } \\
\text { most involved association members }\end{array}$ & Context \\
\hline Residential community & & & Motivations \\
\hline
\end{tabular}

model as the most appropriate model for predicting the expected value of each Secchi measurement (Zuur et al. 2009). We used DOC, lake surface area, percent agriculture land use in the catchment, and presence of zebra mussels as the fixed effects while accounting for the random effects across sites, lakes, and years. The model was run with a Gaussian distribution using the lmer function in the lme4 R package (Bates et al. 2015). Model selection was performed using backward elimination of random and fixed effects via a stepwise regression test using the function step() in the lmertest R package (Kuznetsova et al. 2017). Model ranking by stepwise regression was corroborated using second-order Akaike's Information Criterion adjusted for small sample sizes (AICc; Hurvich and Tsai 1989). Our most parsimonious model (as identified with AICc) was the full model, including all biophysical variables (DOC + lake surface area + percent agricultural land + zebra mussels) and site, lakes, and years as random effects. We used this top model to quantify parameter estimates for the biophysical variables. All predicted and observed water clarity values for each site were aggregated across all years after analysis, obtaining a mean expected water clarity and mean observed water clarity for each site between 2003 and 2013. This was done to remove unaccounted for environmental variability (such as those in climate) that affect the entire region and may skew results.

We identified bright and dark spots among the tested sites $(\mathrm{n}=$ 53), as those sites with residuals deviating by one or more standard deviation (SD) in water clarity from the predicted relationship as determined by our biophysical top model, either positively (bright spots) or negatively (dark spots; Fig. 2). Again, bright and dark spots are not the sites with the greatest or lowest water clarity, but rather those that had the largest magnitudes of deviation from the expected water clarity value generated by the predictive model based on their set biophysical conditions (Cinner et al. 2016, Frei et al. 2018).

\section{Stewardship survey}

In contrast to biophysical drivers, mostly gathered at site level, indicators of stewardship were gathered for each lake $(n=39)$, the scale at which most stewardship actions are organized. At the lake level, we created a survey to assess Bennett et al.'s (2018) four key leverage points of stewardship: actors, motivations, capacities (in the form of social and financial capitals), and actions (Table 1). The survey also assessed the stewardship context of each group based on socioeconomic conditions (development levels, resident community type), as well as additional stewardship and organizational characteristics, including perceived outcomes and communication strategies (see Table 1 and Appendix 1). A previous survey used in a widespread assessment of community stewardship, STEW-MAP: New York City Region, was used to guide formatting, question style, and survey order (Romolini et al. 2016, Svendsen et al. 2016). We contacted 17 active lake associations and two independent lake stewards and distributed the survey to the 13 lake associations and two lake stewards who responded and gave consent to participate. Eleven surveys were completed electronically while two were conducted over the phone.

Fig. 2. Final model, with all 53 sites plotted according to their mean observed Secchi values between 2001 and 2013 and mean expected Secchi from fitted linear mixed effects model.

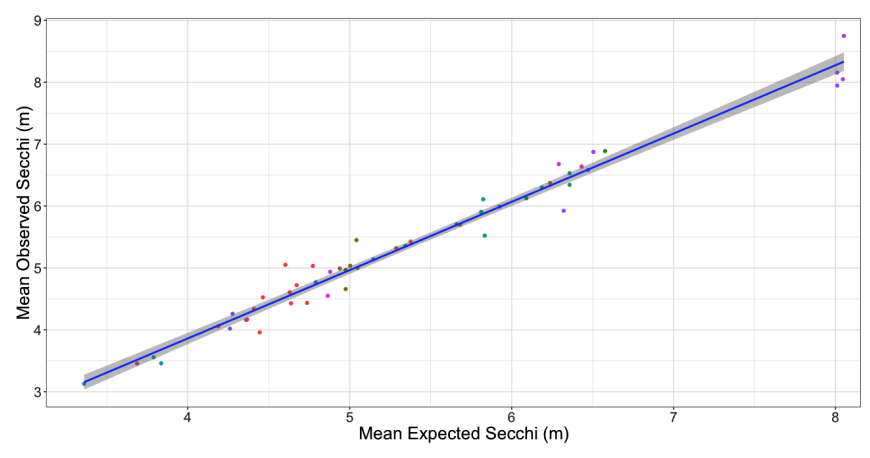

We distributed a survey to all active lake associations identified in the Rideau Valley. We asked questions regarding various 
Table 2. Candidate set of biophysical models predicting water clarity (Secchi disc depth) in the Rideau Valley, Ontario, between 2001 and 2013. (1+secchi) notation indicates a random effect that allows slope to vary as well as intercept. Model ranking using AICc and goodness of fit test (marginal $\mathrm{R}^{2}$ ). $\mathrm{K}=$ number of parameters.

\begin{tabular}{|c|c|c|c|}
\hline Model & $\begin{array}{c}\text { Difference in } \\
\text { AICc }\end{array}$ & $\mathrm{K}$ & Marginal $\mathrm{R}^{2}$ \\
\hline DOC + surfaceArea + perAg + factor $(z m)+(1 \mid$ Lake $)+(1 \mid$ Site $)+(1 \mid$ Year $)$ & 0 & 7 & 0.1406 \\
\hline $\mathrm{DOC}+$ surfaceArea + perAg + factor $(\mathrm{zm})+7.57(1+$ secchi $\mid$ Lake $)+(1+$ secchi|Site $)+(1+$ secchi|Year $)$ & 7.57 & 7 & 0.0328 \\
\hline $\mathrm{DOC}+$ surfaceArea + perAg + factor $(\mathrm{zm})+(1+$ secchi|Site $)+(1+$ secchi|Year $)$ & 91.93 & 6 & 0.1308 \\
\hline $\mathrm{DOC}+$ surfaceArea + perAg + factor $(\mathrm{zm})+(1 \mid$ Site $)+(1 \mid$ Year $)$ & 107.68 & 6 & 0.0658 \\
\hline $\mathrm{OC}+$ surfaceArea + perAg + factor(zm) & 174.92 & 4 & 0.1389 \\
\hline
\end{tabular}

characteristics of stewardship, drawing from the conceptual framework presented in Bennett et al. (2018). Following Svendsen et al. (2016), we also asked questions about the socioeconomic context of the lake.

\section{RESULTS}

\section{Biophysical model of water clarity}

Our biophysical model for water clarity (see Table 2) had a marginal $\mathrm{R}^{2}$ of 0.14 and a conditional $\mathrm{R}^{2}$ of 0.50 (Nakagawa and Schielzeth 2013). Of the biophysical variables included in the model (DOC, lake surface area, percent agriculture in catchment, presence of zebra mussels), only DOC was significantly associated with water clarity, wherein sites with higher DOC had lower water quality (as measured by Secchi depth; Table 3). In predictive modeling the marginal $\mathrm{R}^{2}$, i.e., the goodness of fit of the fixed effects as predictors, is the goodness of fit measurement of interest. Comparatively, in a bright site analysis the conditional $\mathrm{R}^{2}$, i.e., the goodness of fit of the overall model using both fixed and random effects, is the measurement of importance; in this case we consider the fit of the overall model $(0.5)$ to be sufficient for our needs.

Table 3. Parameter estimates from the top biophysical model (as identified using AICc) predicting water clarity (Secchi disc depth) in the Rideau Valley, Ontario, between 2001 and 2013.

\begin{tabular}{lccc}
\hline \hline \multirow{2}{*}{ Model Variable } & \multicolumn{3}{c}{ Water Clarity } \\
\cline { 2 - 4 } & $\begin{array}{c}\text { Parameter } \\
\text { Estimate }\end{array}$ & $\begin{array}{c}\text { Confidence } \\
\text { Interval }\end{array}$ & p-value \\
\hline Dissolved Organic Carbon (DOC) & -0.24 & $0.35--0.13$ & $<0.001$ \\
Lake Surface Area & 0.02 & $-0.01-0.05$ & 0.227 \\
Percent Agricultural Land Use & 0.03 & $-0.01-0.07$ & 0.116 \\
Presence of Zebra Mussels & 0.23 & $-0.44-0.89$ & 0.513 \\
\hline
\end{tabular}

\section{Identification of bright and dark spots of water clarity}

Our analysis designated seven out of 53 sites as bright spots, meaning that they were found to have water clarity exceeding expectations by more than one standard deviation $(\mathrm{SD}=0.25 \mathrm{~m})$ based on the biophysical conditions in our model (Fig. 3). These seven sites were found in five different lakes in the Rideau Valley. Nine sites, on nine different lakes, were designated as dark spots, indicating that they were found to have water quality below expectations (Fig. 4). Two lakes contained both a bright spot and a dark spot (Wolf L., Big Rideau L.). Of the five lakes with bright spot sites, four had active lake associations while one (RVL 47
Tommy L.) had only one landowner on the lake. The four lakes containing bright spot sites that were linked with lake associations were developed, larger lakes, with a percentage of year-round residents close to the regional average of around $20 \%$. Conditions at identified dark spots were variable, with a variety of lake sizes, governance systems, and locations, ranging from a small, low development cottage lake (20 homes, 10\% year-round residency) with high DOC content (Carnahan L.) to a large, very highly developed lake with subdivision-style residential development (525 homes, 50\% year-round residency), heavy shoreline infrastructure, and active recreation facilities (Otty L.). A spatial pattern was apparent connecting a group of three lakes with identified dark spot sites (Long L. West, Elbow L., Carnahan L.; Fig. 5) that were situated at the region with the highest elevation of the watershed in the Township of Central Frontenac. Lakes with bright spot sites were distributed across the entire watershed (Fig. 5).

Fig. 3. Eight bright spot sites (of 53) on seven lakes (of 39) and nine dark spot sites on eight lakes designated from model results.

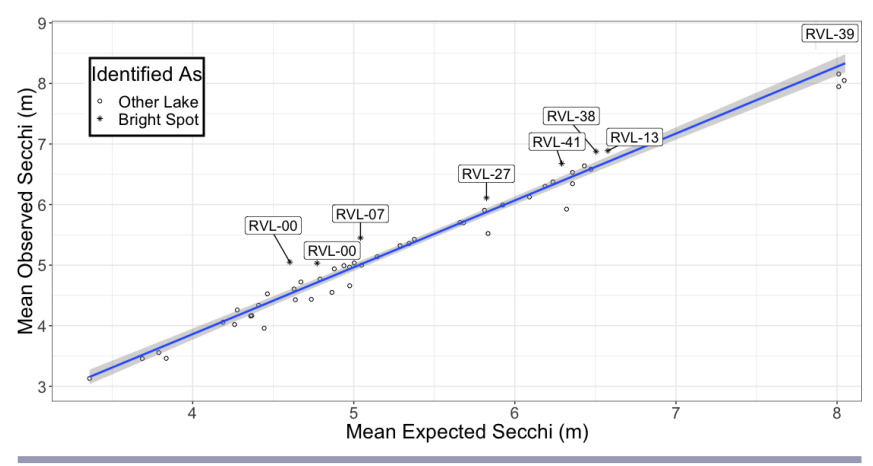

Stewardship characteristics and water clarity bright spots

Of the 17 active lake associations identified in the Rideau Valley, 13 responded to initial contact, and 12 completed our survey (response rate of $71 \%$ ). Three of the lake associations that did not respond to the survey were associated with lakes containing dark spot sites.

Survey results showed commonalities across all lake associations (see Fig. 6). Ten of the 13 associations specified some engagement with "networking," while "monitoring" was most often listed as a group's primary activity. However, no single activity was performed by all associations. Respondents did not perceive 
Fig. 4. Eight bright spot sites (of 53) on seven lakes (of 39) and nine dark spot sites on eight lakes designated from model results.

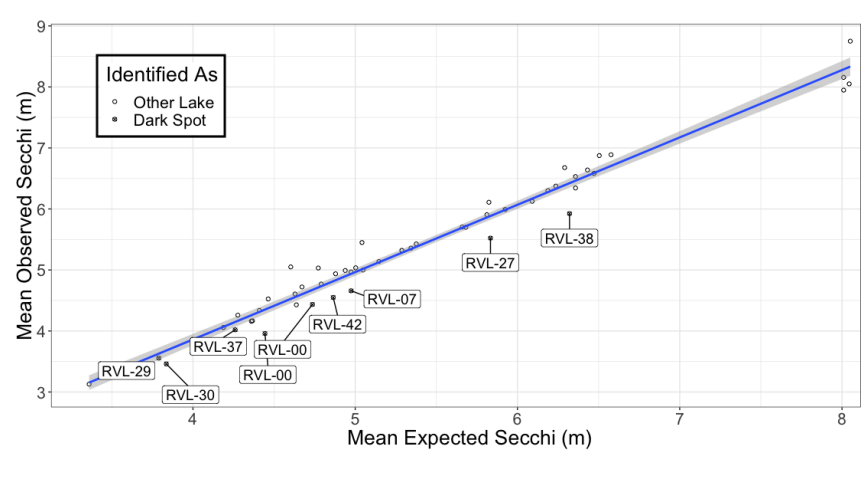

Fig. 5. Lakes with identified bright and dark spot sites in the study area, with the regional center of Perth, Ontario.

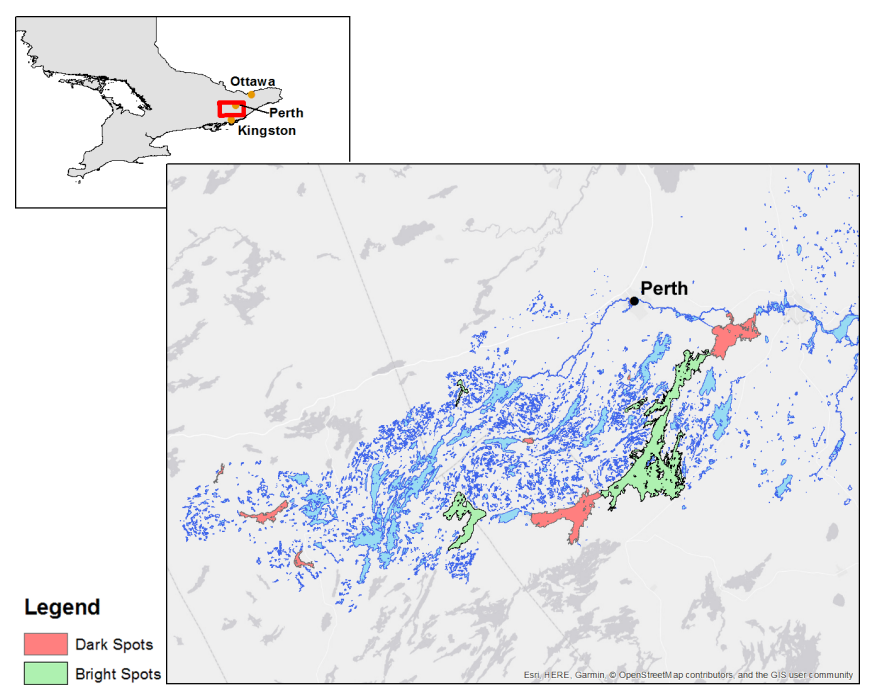

strong benefits resulting from their stewardship work, with similar attitudes toward both potentially beneficial social (i.e., "trust between neighbors") and ecological outcomes (i.e., "habitat protection"). In general, ecological outcomes were perceived as being higher than social outcomes across all groups. Stewards ranked all suggested extrinsic motivations (drawn from Svendsen et al. 2016) very low, indicating little to no motivation to act drawn from climate change, change in development, or larger scale environmental movements. Textual questions suggested that the strongest motivation for this group of stewards was simply "preservation of water quality."

Lake associations associated with bright spot lakes had clear and defined commonalities that differed from all others surveyed (see Fig. 6). All four bright spot lake associations listed either networking or advocacy as their primary activity, with no other lake associations reporting this, indicating that lakes with stewardship associations engaged in larger scale networking and advocacy activities are related to higher water quality outcomes than would be expected given lake biophysical conditions. Furthermore, networking and advocacy were the only activities engaged in by all four bright spot associations, stressing its importance and centrality to these groups' work. When compared to associations working on lakes not containing bright spots, these associations had a higher perception of their own beneficial social outcomes (on average, ranked $3.1 / 10$ vs $2.9 / 10$ ) and a lower perception of their ecological outcomes (2.8/10 vs 3.3/10). Lake associations on lakes that had bright spots also operated on a budget of less than half the average amount (per household) when compared to all lake associations surveyed. No stewardship commonalities could be found for associations on lakes containing dark spot sites because none of these associations responded to the survey.

Fig. 6. A comparison of three key characteristic differences between stewardship groups on lakes containing bright spot sites $(n=4)$ and all other stewardship groups found in the Rideau Valley,Ontario $(n=12)$. Groups on lakes with bright spots operate in a distinctly different way, focusing more strongly on networking and advocacy activities as well as on social benefits, while operating on a far lower budget.

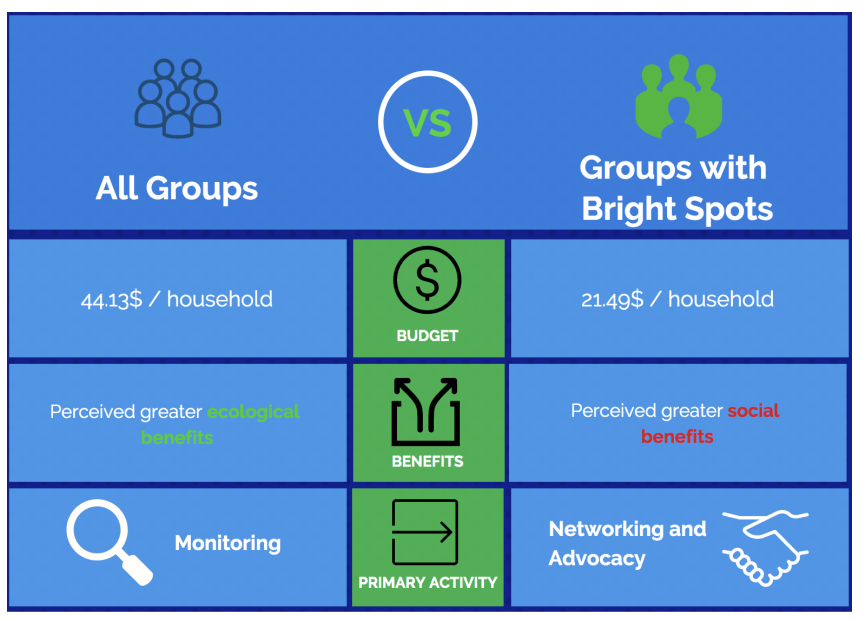

\section{DISCUSSION}

We identified seven sites across the Rideau Valley as bright spots for water clarity, i.e., sites where measured water clarity exceeded that predicted by the biophysical conditions and random temporal and spatial effects of the region. We found that lakes with water clarity bright spots had stewardship groups operating on them in a distinctly different way than stewardship groups working on other lakes in the region. Stewardship groups on lakes with water clarity bright spots put a strong focus on networking and advocacy, diverging from stewardship groups on nonbright spots lakes with a stronger focus on monitoring or other environmentally focused activities. In addition to focusing primarily on networking and advocacy activities, these stewardship groups on lakes with water clarity bright spots perceived greater social benefits than ecological benefits from their work, in contrast to stewardship groups on nonbright spots lakes who perceived greater ecological benefits. Differences in 
water clarity in our models were mainly driven by DOC concentration, with some contribution from lake surface area, percent agricultural land use, and zebra mussel presence.

DOC has been found to be the primary driver of water clarity in an experimental study of small lakes on the Canadian Shield in Ontario (Fee et al. 1996), with increased concentrations of DOC extinguishing light penetration into the water column. Some increases in water clarity could be explained by decreases in DOC, driven by increases in temperature and decreases in precipitation (Schindler 1971) caused by climate change (Fee et al. 1996).

Results showed variation in water clarity between multiple sites within a single lake, with two lakes (Wolf L., Big Rideau L.) containing both a bright spot site and a dark spot site. Often, studies of water clarity will treat lakes as a homogenous system with consistent water quality (Fee et al. 1996, Lathrop et al. 1996, 1999, Gunn et al. 2001). However, for more robust management of lakes, more consideration of the internal dynamics of lakes and differences between basins must be taken into account. For measurements of water clarity and the parameters that drive them, separating lakes into separate measurement sites for each basin is important: dissolved organic carbon can vary between basins and importantly, the effect of stewardship effort may be unevenly focused. However, this study only looked at stewardship at the lake level; future research into how stewardship effort is distributed between basins in large lakes is needed.

Positive outliers have the unique power of being proven solutions that have the potential to be adapted into many contexts (Bennett et al. 2016, Post and Geldmann 2018). This study stands as an additional example of using a bright spots framework to explore the connections between ecological outcomes and variation in management strategies on an unexplored landscape of a lake region. Similar studies have been conducted on a global scale looking at coral reef biomass (Cinner et al. 2016) as well as on a regional scale looking at agricultural landscapes (Frei et al. 2018). Using bright spots studies as templates, managers on many scales can adapt solutions to their own contexts, creating a clear link between conservation research and policies (Cvitanovic and Hobday 2018). Our study points to the importance of managers and local environmental stewards to work together to create new management arrangements using lake associations across a region as a case study. For effective collaboration in other contexts, agents can adapt and create networking arrangements that fit local customs, norms, and requirements (Armitage et al. 2009).

Lakes containing bright spot sites and lake associations whose work is more focused on networking can serve as a model for new management arrangements and strategies to manage lakes for water clarity (Scheffer and van Nes 2007, Keeler et al. 2012). Groups working on lakes with bright spot sites fit the stewardship framework proposed by Masterson et al. (2017) and Enqvist et al. (2019): they engage in building community cohesion and beneficial social outcomes, leading to the agency to engage in larger scale networking and advocacy activities, creating a new management arrangement. Building community trust has the potential to result in tangible ecosystem benefits, such as improved water clarity, as well as extended social benefits, including ongoing learning (Fujitani et al. 2017), adaptive capacity (Armitage et al. 2009), and general community resilience (Campbell et al. 2019).
Networking and advocacy are stewardship strategies that have a relationship with positive water quality and we argue for their utility as a way forward for lake associations and other stewardship groups, although this result is complicated by the implication that groups on lakes with already high water quality may spend more free time networking because they are not compelled to improve water quality though more direct actions. Further study is needed to examine the policies and management arrangements that emerge from stewardship networking strategies, and the differences between specific lakes with and without these collaborations. However, we used a bright spots approach to control for the environmental variables and constraints that underlie this complication, selecting for lakes with higher water quality than expected rather than the highest water quality in the region, leading for us to still argue for the utility of networking strategies.

Although limited by small sample size among lakes $(n=39)$ and responding lake associations $(n=13)$, in this study we utilized a decade-long time series of water quality measurements $(n=490)$ to obtain insights on lake management, in particular with regard to local environmental stewardship. Although further study is needed to determine how exactly groups can gain the community agency identified among these groups and develop an effective policy program, this study points to the importance of working toward networking and advocacy goals as a future for lake stewardship groups in the Rideau Valley.

\section{CONCLUSION}

Understanding drivers of water quality is important for maintaining, enhancing, and supporting the ecosystem services provided by lake systems. Of the 53 sites, 39 lakes, and 13 lake associations studied in the Rideau Valley, lakes with stewardship associations engaged in larger scale networking and advocacy activities were associated with higher water quality outcomes than would be expected given lake biophysical conditions. Understanding which stewardship activities are associated with a significant difference in ecological outcomes can help point to strategies to utilize stewardship as a management tool to improve water quality.

Responses to this article can be read online at: http://www.ecologyandsociety.org/issues/responses. php/11073

\footnotetext{
Acknowledgments:

We thank all involved with the Watershed Watch Program at the Rideau Valley Conservation Authority, from field staff to volunteers. Particular thanks are given to Mike Yee and Sarah MacLeod-Neilson for their support and contribution of data. Lastly, we thank the dedicated group of lake association stewards in the Rideau Valley who took the time to complete our survey, discuss the project, and work tirelessly year-round to support, protect, and improve their lakes.
} 


\section{LITERATURE CITED}

Ahmed, F. 2010. Numerical modeling of the Rideau Valley Watershed. Natural Hazards 55(1):63-84. https://doi.org/10.1007/ s11069-010-9588-4

Armitage, D. R., R. Plummer, F. Berkes, R. I. Arthur, A. T. Charles, I. J. Davidson-Hunt, A. P. Diduck, N. C. Doubleday, D. S. Johnson, M. Marschke, P. McConney, E. W. Pinkerton, and E. K. Wollenberg. 2009. Adaptive co-management for socialecological complexity. Frontiers in Ecology and the Environment 7(2):95-102. https://doi.org/10.1890/070089

Barbiero, R. P., and M. L. Tuchman. 2004. Long-term dreissenid impacts on water clarity in Lake Erie. Journal of Great Lakes Research 30(4):557-565. https://doi.org/10.1016/S0380-1330(04) 70371-8

Bates, D., M. Mächler, B. Bolker, and S. Walker. 2015. Fitting linear mixed-effects models using lme4. Journal of Statistical Software 67(1):1-48. https://doi.org/10.18637/jss.v067.i01

Bennett, E. M., M. Solan, R. Biggs, T. McPhearson, A. V. Norström, P. Olsson, L. Pereira, G. D. Peterson, C. RaudseppHearne, F. Biermann, S. R. Carpenter, E. C. Ellis, T. Hichert, V. Galaz, M. Lahsen, M. Milkoreit, B. Martin López, K. A. Nicholas, R. Preiser, G. Vince, J. M. Vervoort, and J. Xu. 2016. Bright spots: seeds of a good Anthropocene. Frontiers in Ecology and the Environment 14(8):441-448. https://doi.org/10.1002/ fee.1309

Bennett, N. J., T. S. Whitty, E. Finkbeiner, J. Pittman, H. Bassett, S. Gelcich, and E. H. Allison. 2018. Environmental stewardship: a conceptual review and analytical framework. Environmental Management 61(4):597-614. https://doi.org/10.1007/s00267-017-0993-2

Brauman, K. A., G. C. Daily, T. K. Duarte, and H. A. Mooney. 2007. The nature and value of ecosystem services: an overview highlighting hydrologic services. Annual Review of Environment and Resources 32(1):67-98. https://doi.org/10.1146/annurev. energy.32.031306.102758

Campbell, L. K., E. Svendsen, N. F. Sonti, S. J. Hines, and D. Maddox. 2019. Green readiness, response, and recovery: a collaborative synthesis. General Technical Report NRS-P-185. U. S. Forest Service, Northern Research Station, Newtown Square, Pennsylvania, USA. https://doi.org/10.2737/NRS-GTR-P-185

Cinner, J. E., C. Huchery, M. A. MacNeil, N. A. J. Graham, T. R. McClanahan, J. Maina, E. Maire, J. N. Kittinger, C. C. Hicks, C. Mora, E. H. Allison, S. D'Agata, A. Hoey, D. A. Feary, L. Crowder, I. D. Williams, M. Kulbicki, L. Vigliola, L. Wantiez, G. Edgar, R. D. Stuart-Smith, S. A. Sandin, A. L. Green, M. J. Hardt, M. Beger, A. Friedlander, S. J. Campbell, K. E. Holmes, S. K. Wilson, E. Brokovich, A. J. Brooks, J. J. Cruz-Motta, D. J. Booth, P. Chabanet, C. Gough, M. Tupper, S. C. A. Ferse, U. R. Sumaila, and D. Mouillot. 2016. Bright spots among the world's coral reefs. Nature 535(7612):416-419. https://doi.org/10.1038/nature18607

Cvitanovic, C., and A. J. Hobday. 2018. Building optimism at the environmental science-policy-practice interface through the study of bright spots. Nature Communications 9:3466. https://doi. org/10.1038/s41467-018-05977-w

Davies-Colley, R. J., and D. G. Smith. 2001. Turbidity suspended sediment, and water clarity: a review. JAWRA Journal of the
American Water Resources Association 37(5):1085-1101. https:// doi.org/10.1111/j.1752-1688.2001.tb03624.x

Enqvist, J. P., L. K. Campbell, R. C. Stedman, and E. S. Svendsen. 2019. Place meanings on the urban waterfront: a typology of stewardships. Sustainability Science 14(3):589-605. https://doi. org/10.1007/s11625-019-00660-5

Fahnenstiel, G. L., G. A. Lang, T. F. Nalepa, and T. H. Johengen. 1995. Effects of zebra mussel (Dreissena polymorpha) colonization on water quality parameters in Saginaw Bay, Lake Huron. Journal of Great Lakes Research 21(4):435-448. https:// doi.org/10.1016/S0380-1330(95)71057-7

Fee, E. J., R. E. Hecky, S. E. M. Kasian, and D. R. Cruikshank. 1996. Effects of lake size, water clarity, and climatic variability on mixing depths in Canadian Shield lakes. Limnology and Oceanography 41(5):912-920. https://doi.org/10.4319/1o.1996.41.5.0912

Frei, B., D. Renard, M. G. E. Mitchell, V. Seufert, R. ChaplinKramer, J. M. Rhemtulla, and E. M. Bennett. 2018. Bright spots in agricultural landscapes: identifying areas exceeding expectations for multifunctionality and biodiversity. Journal of Applied Ecology 55(6):2731-2743. https://doi.org/10.1111/1365-$\underline{2664.13191}$

Fujitani, M., A. McFall, C. Randler, and R. Arlinghaus. 2017. Participatory adaptive management leads to environmental learning outcomes extending beyond the sphere of science. Science Advances 3(6):e1602516. https://doi.org/10.1126/sciadv.1602516

Gibbs, J. P., J. M. Halstead, K. J. Boyle, and J.-C. Huang. 2002. A hedonic analysis of the effects of lake water clarity on New Hampshire lakefront properties. Agricultural and Resource Economics Review 31(1):39-46. https://doi.org/10.1017/ $\underline{\mathrm{S} 1068280500003464}$

Gunn, J. M., E. Snucins, N. D. Yan, and M. T. Arts. 2001. Use of water clarity to monitor the effects of climate change and other stressors on oligotrophic lakes. Environmental Monitoring and Assessment 67(1-2):69-88. https://doi.org/10.1023/a:1006435721636

Hall, R. I., and J. P. Smol. 1996. Paleolimnological assessment of long-term water-quality changes in south-central Ontario lakes affected by cottage development and acidification. Canadian Journal of Fisheries and Aquatic Sciences 53(1):1-17. https://doi. org/10.1139/f95-171

Halseth, G., and M. W. Rosenberg. 1995. Cottagers in an urban field. Professional Geographer 47(2):148-159. https://doi. org/10.1111/j.0033-0124.1995.00148.x

Hurvich, C. M., and C.-L. Tsai. 1989. Regression and time series model selection in small samples. Biometrika 76(2):297-307. https://doi.org/10.1093/biomet/76.2.297

Jeppesen, E., M. Søndergaard, N. Mazzeo, M. Meerhoff, C. C. Branco, V. L. M. Huszar, and F. Scasso. 2005. Lake restoration and biomanipulation in temperate lakes: relevance for subtropical and tropical lakes. Pages 340-360 in M. V. Reddy, editor. Restoration and management of tropical eutrophic lakes. CRC, Boca Raton, Florida, USA.

Keeler, B. L., S. Polasky, K. A. Brauman, K. A. Johnson, J. C. Finlay, A. O'Neill, K. Kovacs, and B. Dalzell. 2012. Linking water quality and well-being for improved assessment and valuation of 
ecosystem services. Proceedings of the National Academy of Sciences 109(45):18619-18624. https://doi.org/10.1073/pnas.1215991109

Kramer, D. B. 2007. Determinants and efficacy of social capital in lake associations. Environmental Conservation 34(03):186-194. https://doi.org/10.1017/S0376892907004171

Kuznetsova, A., P. B. Brockhoff, and R. H. B. Christensen. 2017. lmerTest package: tests in linear mixed effects models. Journal of Statistical Software 82(13):1-26. http://doi.org/10.18637/jss.v082. $\underline{\mathrm{i} 13}$

Lathrop, R. C., S. R. Carpenter, and D. M. Robertson. 1999. Summer water clarity responses to phosphorus, Daphnia grazing, and internal mixing in Lake Mendota. Limnology and Oceanography 44(1):137-146. https://doi.org/10.4319/1o.1999.44.1.0137

Lathrop, R. C., S. R. Carpenter, and L. G. Rudstam. 1996. Water clarity in Lake Mendota since 1900: responses to differing levels of nutrients and herbivory. Canadian Journal of Fisheries and Aquatic Sciences 53(10):2250-2261. https://doi.org/10.1139/ cjfas-53-10-2250

Masterson, V. A., R. C. Stedman, J. Enqvist, M. Tengö, M. Giusti, D. Wahl, and U. Svedin. 2017. The contribution of sense of place to social-ecological systems research: a review and research agenda. Ecology and Society 22(1):49. https://doi.org/10.5751/ ES-08872-220149

Nakagawa, S., and H. Schielzeth. 2013. A general and simple method for obtaining $\mathrm{R}^{2}$ from generalized linear mixed-effects models. Methods in Ecology and Evolution 4(2):133-142. https:// doi.org/10.1111/j.2041-210x.2012.00261.x

Ontario Ministry of Natural Resources and Forestry. 2017. User guide for Ontario flow assessment tool (OFAT). Ontario Ministry of Natural Resources and Forestry, Peterborough, Ontario, Canada. [online] URL: https://www.sse.gov.on.ca/sites/MNRPublicDocs/EN/CMID/OFAT $\% 20-\% 20$ User $\% 20$ Guide $\% 20-\% 20$ eng. pdf

Ostrom, E. 2009. A general framework for analyzing sustainability of social-ecological systems. Science 325 (5939):419-422. https://doi.org/10.1126/science.1172133

Peterson, G. D., T. D. Beard Jr, B. E. Beisner, E. M. Bennett, S. R. Carpenter, G. S. Cumming, C. L. Dent, and T. D. Havlicek. 2003. Assessing future ecosystem services: a case study of the Northern Highlands Lake District, Wisconsin. Conservation Ecology 7(3):1. https://doi.org/10.5751/ES-00557-070301

Post, G., and J. Geldmann. 2018. Exceptional responders in conservation: exceptional responders in conservation. Conservation Biology 32(3):576-583. https://doi.org/10.1111/cobi.13006

Postel, S. L., and B. H. Thompson Jr. 2005. Watershed protection: capturing the benefits of nature's water supply services. Natural Resources Forum 29(2):98-108. https://doi.org/10.1111/ j.1477-8947.2005.00119.x

R Core Team. 2018. R: A language and environment for statistical computing. R Foundation for Statistical Computing, Vienna, Austria.

Romolini, M., R. P. Bixler, and J. M. Grove. 2016. A socialecological framework for urban stewardship network research to promote sustainable and resilient cities. Sustainability 8(9):956. https://doi.org/10.3390/su8090956

Scheffer, M., S. H. Hosper, M.-L. Meijer, B. Moss, and E. Jeppesen. 1993. Alternative equilibria in shallow lakes. Trends in Ecology \& Evolution 8(8):275-279. https://doi.org/10.1016/0169-5347 (93)90254-M

Scheffer, M., and E. H. van Nes. 2007. Shallow lakes theory revisited: various alternative regimes driven by climate, nutrients, depth and lake size. Shallow Lakes in a Changing World 584 (1):455-466. https://doi.org/10.1007/978-1-4020-6399-2 41

Schindler, D. W. 1971. Light, temperature, and oxygen regimes of selected lakes in the Experimental Lakes Area, Northwestern Ontario. Journal of the Fisheries Research Board of Canada 28 (2):157-169. https://doi.org/10.1139/f71-029

Soranno, P. A., S. L. Hubler, S. R. Carpenter, and R. C. Lathrop. 1996. Phosphorus loads to surface waters: a simple model to account for spatial pattern of land use. Ecological Applications 6 (3):865-878. https://doi.org/10.2307/2269490

Stefan, H. G., R. B. Ambrose, and M. S. Dortch. 1989. Formulation of water quality models for streams, lakes, and reservoirs, modeler's perspective. Final Report, U.S. Army Corps of Engineers, Vicksburg, Mississippi, USA.

Svendsen, E. S., L. K. Campbell, D. R. Fisher, J. J. T. Connolly, M. L. Johnson, N. F. Sonti, D. H. Locke, L. M. Westphal, C. L. Fisher, J. M. Grove, M. Romolini, D. J. Blahna, and K. L. Wolf. 2016. Stewardship mapping and assessment project: a framework for understanding community-based environmental stewardship. General Technical Report NRS-156. U.S. Forestry Service, Northern Research Station, Newtown Square, Pennsylvania, USA. https://doi.org/10.2737/NRS-GTR-156

Tong, S. T. Y., and W. Chen. 2002. Modeling the relationship between land use and surface water quality. Journal of Environmental Management 66(4):377-393. https://doi.org/10.1006/ jema.2002.0593

Wolf, K. L., D. J. Blahna, W. Brinkley, and M. Romolini. 2013. Environmental stewardship footprint research: linking human agency and ecosystem health in the Puget Sound region. Urban Ecosystems 16(1):13-32. https://doi.org/10.1007/s11252-011-0175-6

Zuur, A. F., E. N. Ieno, N. Walker, A. A. Saveliev, and G. M. Smith, editors. 2009. Mixed effects models and extensions in ecology with $R$. Springer, New York, New York, USA. https://doi. org/10.1007/978-0-387-87458-6 
Appendix 1: Full text of the survey that was sent to all active lake association groups in the Rideau Valley, as identified by the Rideau Valley Conservation Authority. Groups were contacted via email and surveys were completed electronically. We obtained a response rate of $71 \%$, with 12 of 17 active associations completing the survey.

\section{Social-Ecological Bright Spots Among Lakes in the Rideau Valley}

Welcome to the survey of lake associations as part of the Social-Ecological Bright Spots project at McGill University. The survey should take roughly about 60-120 minutes of your time. If you would rather conduct an in person interview over Skype or Telephone and have answers transcribed, please contact the PI directly. If you are unable to answer these questions, please reach out to another member of the association and ask them to fill out the survey or help you answer. Thank you for your participation!

\section{Section A: Contact Information}

This information will remain confidential. Your name, email, phone number, or any other identifying personal information will not be shared outside the research team. We may contact you to follow up on or clarify answers given in the survey.

\begin{tabular}{|c|c|}
\hline Your Name & \\
\hline Your Email & \\
\hline Your Phone Number & \\
\hline $\begin{array}{c}\text { Your Role in the } \\
\text { Lake Association }\end{array}$ \\
\hline
\end{tabular}

\section{Section B: Basic Association Information}

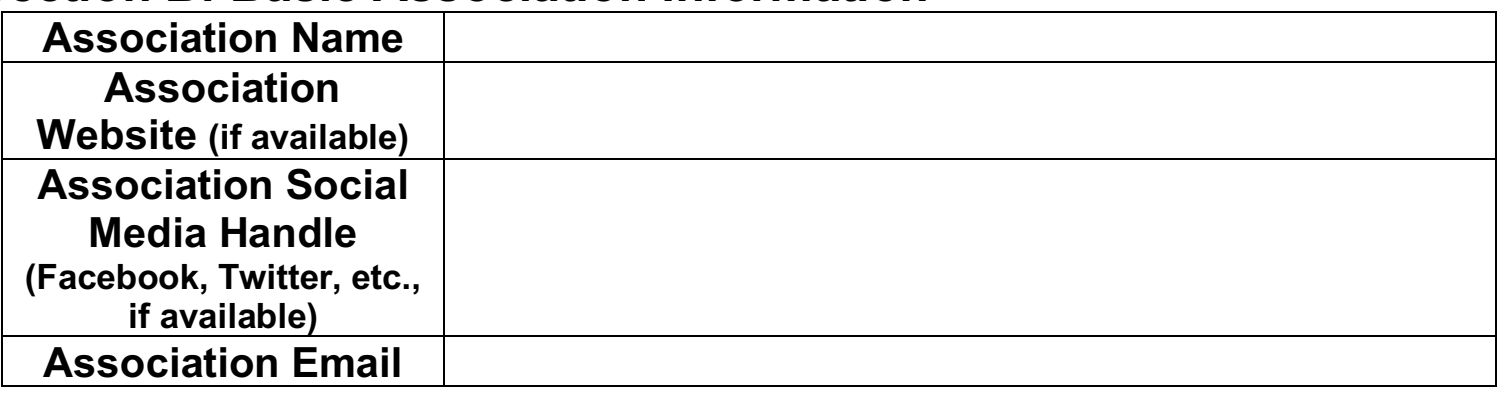


Does your group do any of the following activities? Yes or No. In the right side column, please indicate what percentage of association time is spent on this category.

\begin{tabular}{|l|l|r|}
\hline Activity & \multicolumn{1}{|c|}{ Yxample } & $\%$ \\
\hline $\begin{array}{l}\text { Conserve or } \\
\text { preserve the } \\
\text { environment on or } \\
\text { around your lake }\end{array}$ & Protected park areas, no wake zones & $\%$ \\
\hline $\begin{array}{l}\text { Manage areas of } \\
\text { your lake }\end{array}$ & $\begin{array}{l}\text { Garbage clean up, shoreline plantings, } \\
\text { invasive species removal }\end{array}$ & $\%$ \\
\hline $\begin{array}{l}\text { Transform local } \\
\text { systems }\end{array}$ & $\begin{array}{l}\text { Encourage renewable energy, septic } \\
\text { re-inspection programs }\end{array}$ & $\%$ \\
\hline Lake Monitoring & $\begin{array}{l}\text { Water quality testing (independent of } \\
\text { RVCA), invasive species monitoring }\end{array}$ & $\%$ \\
\hline $\begin{array}{l}\text { Advocacy or } \\
\text { Planning }\end{array}$ & Production of a lake management plan \\
\hline $\begin{array}{l}\text { Environmental } \\
\text { Education }\end{array}$ & $\begin{array}{l}\text { Workshops on stewardship, invasive } \\
\text { species awareness program, summer } \\
\text { camp focused on environment for } \\
\text { young cottagers }\end{array}$ & $\%$ \\
\hline $\begin{array}{l}\text { Networking with } \\
\text { local government } \\
\text { agencies }\end{array}$ & Working with RVCA, township & $\%$ \\
\hline None of the above & Please Explain: & $\%$ \\
\hline
\end{tabular}

Of these, which is your primary activity? Check only one.

\begin{tabular}{|l|l|}
\hline Conserving & \\
\hline Managing & \\
\hline Transforming & \\
\hline Monitoring & \\
\hline Advocacy & \\
\hline Education & \\
\hline Networking & \\
\hline None of the Above & \\
\hline
\end{tabular}

\section{Section C: Community Information}

If possible, please provide a figure or estimate for total number of cottages/homes on your lake: 
If possible, please provide a figure or estimate for total number of residents or cottagers on your lake:

How many cottages/homes are occupied year-round? Provide a percentage.

\section{$\%$}

Are most folks involved in your association year-round residents or seasonal cottagers? Check only one.

\begin{tabular}{|l|l|}
\hline Seasonal & \\
\hline Year-Round & \\
\hline
\end{tabular}

Where are most residents on the lake from? Check only one.

\begin{tabular}{|c|c|}
\hline Local (Lanark, Leeds and Grenvile, & \\
Frontenac Counties) & \\
\hline Eastern Ontario (incl. Ottawa and & \\
Kingston) & \\
\hline Elsewhere in Ontario & \\
\hline United States & \\
\hline Elsewhere in Canada & \\
\hline
\end{tabular}

Where are most lake association volunteers from? Check only one.

\begin{tabular}{|c|}
\hline $\begin{array}{c}\text { Local (Lanark, Leeds and Grenvile, } \\
\text { Frontenac Counties) }\end{array}$ \\
\hline $\begin{array}{c}\text { Eastern Ontario (incl. Ottawa and } \\
\text { Kingston) }\end{array}$ \\
\hline Elsewhere in Ontario \\
\hline United States \\
\hline Elsewhere in Canada \\
\hline
\end{tabular}

Do people involved in the lake association also participate in one or more of the following activities? Check all that apply.

\begin{tabular}{|l|l|}
\hline Hunting & \\
\hline Fishing & \\
\hline Gardening/Farming & \\
\hline
\end{tabular}




\section{Section D: Networking}

Please list groups with which you regularly collaborate on environmental projects or programs:

Please list groups that you go to for knowledge, data, or expertise relating to environmental issues

Please list groups that you lobby or advise regarding environmental or planning policy

Please list groups from which you have received resources - funding or materials.

Section E: Impacts

What major changes or outcomes does your lake association wish to see from your stewardship work? Please be as specific as possible. 
Do you track metrics about your activities? Write in Yes or No

If Yes, which metrics do you track? Would you be open to providing these metrics to the research team? Metric Can provide? Yes or No

For the statements below, check off your agreement with the statement on a scale of 1 (strongly disagree) to 5 (strongly agree)

a) Our group has improved the following social outcomes in our community

a. Community Participation

\begin{tabular}{|c|c|c|c|c|}
\hline 1 & 2 & 3 & 4 & 5 \\
\hline
\end{tabular}

b. Trust Between Neighbours

\begin{tabular}{|l|l|l|l|l|}
\hline 1 & 2 & 3 & 4 & 5 \\
\hline & & & & \\
\hline
\end{tabular}

c. Influence on Policy

\begin{tabular}{|l|l|l|l|l|}
\hline 1 & 2 & 3 & 4 & 5 \\
\hline
\end{tabular}

b) Our group has improved the following environmental outcomes in our community

a. Plants and Habitat Quality

\begin{tabular}{|l|l|l|l|l|}
\hline 1 & 2 & 3 & 4 & 5 \\
\hline & & & & \\
\hline
\end{tabular}

b. Water Quality

\begin{tabular}{|l|l|l|l|l|}
\hline 1 & 2 & 3 & 4 & 5 \\
\hline & & & & \\
\hline
\end{tabular}

c. Land Protection 


\begin{tabular}{|l|l|l|l|l|}
\hline 1 & 2 & 3 & 4 & 5 \\
\hline & & & & \\
\hline
\end{tabular}

c) How influential have the following events and processes been on your group's work?

a. Extreme Weather

\begin{tabular}{|l|l|l|l|l|}
\hline 1 & 2 & 3 & 4 & 5 \\
\hline & & & & \\
\hline
\end{tabular}

b. Climate Change

\begin{tabular}{|c|c|c|c|c|}
\hline 1 & 2 & 3 & 4 & 5 \\
\hline & & & & \\
\hline
\end{tabular}

c. Financial Crises

\begin{tabular}{|l|l|l|l|l|}
\hline 1 & 2 & 3 & 4 & 5 \\
\hline & & & & \\
\hline
\end{tabular}

d. Changes in Elected Officials

\begin{tabular}{|l|l|l|l|l|}
\hline 1 & 2 & 3 & 4 & 5 \\
\hline & & & & \\
\hline
\end{tabular}

e. Social Movements

\begin{tabular}{|c|c|c|c|c|}
\hline 1 & 2 & 3 & 4 & 5 \\
\hline
\end{tabular}

f. Development or Rezoning Plans

\begin{tabular}{|c|c|c|c|c|c|}
\hline 1 & 2 & & 3 & 4 & 5 \\
\hline & & & & & \\
\hline
\end{tabular}

\section{Section F: Additional Information}

Which of the following organizing tools does your association use? Check all that apply

Email List

Physical Newsletter

Social Media

(Facebook, Twitter, etc)

Word of Mouth

Other? Please Specify. 
How many hours a week are generally spent participating in association activities overall?

What is your expected yearly budget for 2018?

Remember, like all questions in the survey, this will be kept confidential and is only for comparison purposes

$\$$

Approximately what proportion of your budget comes from the following sources? Please ensure the proportions sum to $100 \%$

\begin{tabular}{|l|r|}
\hline Government & $\%$ \\
\hline Foundations & $\%$ \\
\hline Corporations & $\%$ \\
\hline Individual Giving & $\%$ \\
\hline Membership & $\%$ \\
Fees & $\%$ \\
\hline Service Fees & $\%$ \\
\hline Other & $\%$ \\
\hline
\end{tabular}

Please Specify "Other" sources

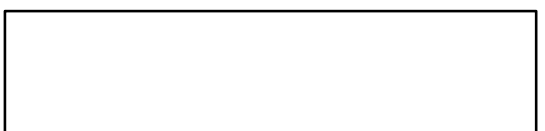

How much is your association's membership fee?

$\$$

Must every cottager/resident on the lake pay association dues or fees? Fill in Yes or No

If no, do non-paying residents opt-in to paying (must join the association) or opt-out (members of the association as a default)? Write in out-in or opt-out 
Personally, what are your main motivations for participating in your lake association?

As an association, what is your greatest accomplishment?

\section{Section G: Final Section}

Would you like to be contacted with final results of the project? Yes or No

Do you have any final thoughts? Share with us any additional information about your group or this survey that you think is important. 
This concludes the survey.

Thank you for your participation! 